\title{
Modeling of water balance response to an extreme future scenario in the Ötztal catchment, Austria
}

\author{
C. Tecklenburg ${ }^{1}{ }^{*}$, T. Francke ${ }^{1}$, C. Kormann ${ }^{1}$, and A. Bronstert ${ }^{1}$ \\ ${ }^{1}$ Institute of Earth and Environmental Science, University of Potsdam, 14476 Potsdam, Germany \\ *now at: Helmholtz Centre Potsdam GFZ German Research Centre for Geosciences, 14473 Potsdam, Germany
}

Correspondence to: C. Tecklenburg (christina.tecklenburg@gfz-potsdam.de)

Received: 2 February 2012 - Revised: 31 July 2012 - Accepted: 4 November 2012 - Published: 11 December 2012

\begin{abstract}
The aim of the study was to investigate the impact of climate change on the water balance of the Ötztaler Ache catchment in Tyrol, Austria. For this purpose the conceptual hydrological model HBV-D REG was applied. First, the model was calibrated and validated using current observed climate and discharge data. Second, the calibrated model was applied with reanalysis data. Third, downscaled climate scenarios from 2010 to 2099 served as input data to the HBVD REG. Thereby two extreme land cover scenarios were considered: for water balance modeling a constant glacier coverage from today and additionally for runoff simulations a complete loss of glaciered area. The downscaled climate data were generated with the expanded downscaling method. Scenario simulations indicated an increase in annual areal temperature by $3.4^{\circ} \mathrm{C}$ and a slight decrease in annual areal precipitation by $89 \mathrm{~mm}$ in the next one hundred years. According to the hydrological modeling, these climate changes caused an increase in evapotranspiration and a decrease in snow coverage. Furthermore model simulations showed an increase in winter and spring runoff, whereas summer runoff was highly sensitive to glacier coverage and decreased with complete loss of glacier coverage.
\end{abstract}

\section{Introduction}

The Alps are often called the water towers of Europe (Veit, 2002). The water from the Alps is of superregional significance for drinking water supply, irrigation and hydropower (Psenner and Lackner, 2006). Glaciers of the Alps are an important seasonal storage of water and furthermore, the presence of glaciers reduces the year-to-year variability in catchment runoff (Röthlisberger and Lang, 1987).
In the Alps the observed temperature increase in the last century was already the twice of the world wide average. It is expected that hydrological condition in catchments in mountain areas are highly sensitive to future climate changes (European Environment Agency, 2009).

For prediction of future changes in hydrological circles in mountain areas conceptual hydrological models with parsimonious structure were often used as they have the advantage of limited need of input data. One major challenge in hydrological modeling in high mountain areas is the generation of spatial distribution of meteorological variables, which are highly variable. This problem is often solved using altitude gradients in extrapolation of climate station data (e.g. HBV, Bergström, 1995; GCM SOCONT, Schaefli et al., 2005). However, previous studies showed that the distribution of temperature and precipitation are related to further orographic factors like geographical location, slope and exposure (e.g. Gómez et al., 2008; Marquinez et al., 2003).

Global circulation models (GCM) can provide data for climate change studies. The disadvantage of the output of GCM is their low spatial resolution, which makes it difficult to use them for models requiring local climate data. The scale issue is typically solved with statistical or dynamical downscaling methods (Wilby and Wigley, 1997). To test the applied downscaling method, a comparison between observed climate data and reanalysis data, downscaled climate data from observed atmospheric field, can be carried out (Bürger, 2002; Menzel and Bürger, 2002).

In this study we applied the conceptual hydrological model HBV-D REG (Tecklenburg et al., 2012) using local climate scenarios generated with the expanded downscaling technique (EDS, Bürger, 2002). The HBV-D REG considers orographical variability in climate data using a multivariate 
regression algorithm in climate data interpolation. The focus of this study was to investigate the impact of future climate change on the water balance of the Ötztal under the assumption of present glaciation. Furthermore the study examined the impact of glacier coverage on future runoff predictions using the assumption of constant present glaciation and complete loss of glaciers as two extreme land cover scenarios.

\section{Study site}

Our investigation focused on the catchment of the Ötztaler Ache in Tyrol, Austria, a tributary of the river Inn (Fig. 1). The study site includes the area upstream of gauge Brunau located $2.2 \mathrm{~km}$ upstream of the estruar in the river Inn $\left(887 \mathrm{~km}^{2}\right)$. The catchment has a length of $65 \mathrm{~km}$ aligned in flow direction north-south with altitudes ranging from $703 \mathrm{~m}$ to $3748 \mathrm{~m}$ a.s.l. (Fig. 1). The valley is dominated by grassland and coniferous woodland. Steep slopes are sparsely vegetated. The Ötztal is partially glaciated (14\%, BMLFUW, 2007) (Fig. 1). Spring and summer runoff are highly dynamic and controlled by precipitation, snow and glacier melt. In contrast to that, winter runoff is characterized by low flow conditions. Average monthly runoff from June to August is 2.5 times higher than the mean annual runoff $\left(31 \mathrm{~m}^{3} \mathrm{~s}^{-1}\right.$, Hydrographischer Dienst in Österreich, 2009). Precipitation is highly variable in space and time. Depending on the location of the climate station, mean annual precipitations range from $623 \mathrm{~mm}$ to $982 \mathrm{~mm}$ (Hydrographischer Dienst in Österreich, 2009). Average annual temperature at Oetz (760 m a.s.l.) is $7.3^{\circ} \mathrm{C}$ and decreases with increasing elevation to $2.1^{\circ} \mathrm{C}$ at Obergurgl (1938 $\mathrm{m}$ a.s.l.) (Hydrographischer Dienst in Österreich, 2009).

\section{Methods and materials}

\subsection{Hydrological model HBV-D}

In our study we applied the HBV-D REG, an enhanced version of the HBV-D/HBV. The conceptual runoff model HBV was originally developed at the Swedish Meteorological and Hydrological Institute (SMHI). It is a semidistributed model involving the most important runoff generation processes using a simple robust structure to adapt physical complexity to a standard climatological measurement network (Bergström, 1995). The structure of the model involves three main routines: (1) snow and glacier routine calculating melt rates with the degree-day-formula, (2) soil moisture routine calculating actual evapotranspiration and soil moisture and (3) response and routing routine transferring storage contents to catchment runoff. In the HBV-D model a catchment can be divided into subcatchments, which can further be divided into ten elevation zones and 15 vegetation zones (Krysanova et al., 1999). A comparison of observed and simulated discharge could be carried out at the catchment outlet and for

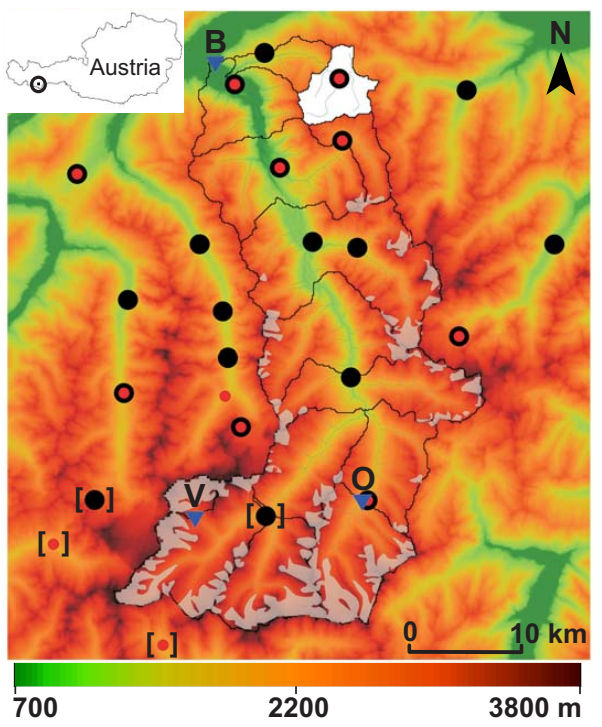

Fig. 1. Overview of Ötztaler Ache catchment including gauges (blue triangular) Brunau (B), Vernagtbach (V) and Obergurgl (O), precipitation stations (black circles) and temperature stations (red circles). Brackets mark the stations for which downscaled data were not available. Catchment and subcatchments are delineated in black. Due to a man made outlet one subcatchment was not contributing and in the modeling procedure not considered (white). Glacier covered areas are presented in silver. Altitude ranges from $700 \mathrm{~m}$ a.s.l. (green) to $3800 \mathrm{~m}$ a.s.1. (brown).

subcatchments without inflow. Glacier coverage and vegetation zones are given as relative area of each elevation zone and assumed to be constant throughout the simulation period. The HBV-D REG contains a refinement in the data input procedure (from subcatchment to elevation zones) and in climate data interpolation in order to improve the representation of spatial variability in climate data. The HBV-D REG uses multivariate regression models to interpolate precipitation and temperature data. The multivariate regression models consider the explanatory variables altitude, slope exposure, geographical location and occurrence of precipitation. The regression models explaining the spatial distribution of temperature and precipitation are estimated for each simulation day using a backward selection approach. For more information of the applied model the reader is referred to Tecklenburg (2011) and Tecklenburg et al. (2012).

\subsection{Data set}

For the model set up we used a digital elevation model with a $100 \mathrm{~m} \times 100 \mathrm{~m}$ resolution to define catchment and subcatchments (Fig. 1) and a landuse map to define the vegetation zones and glacier coverage. A detailed description is given in Tecklenburg (2011) and Tecklenburg et al. (2012). For model calibration and validation we used daily values of measured precipitation from 21 stations, measured temperature data from 12 stations and measured discharge data from three 
Table 1. Goodness measures (NSI, LNSI, VE) of calibrated model for calibration period (cal.) and validation period (val.) using measured data (MEA) and reanalysis data (ANA) as model input data. "na" stands for not available.

\begin{tabular}{|c|c|c|c|c|c|c|c|}
\hline \multirow[b]{2}{*}{ Gauge } & \multirow[b]{2}{*}{ Period } & \multicolumn{2}{|c|}{ NSI } & \multicolumn{2}{|c|}{ LNSI } & \multicolumn{2}{|c|}{$\mathrm{VE}$} \\
\hline & & MEA & ANA & MEA & ANA & MEA & ANA \\
\hline \multirow[t]{2}{*}{ Brunau } & cal. & 0.91 & 0.85 & 0.95 & 0.94 & 0.05 & 0.01 \\
\hline & val. & 0.91 & 0.85 & 0.84 & 0.94 & 0.08 & 0.07 \\
\hline \multirow[t]{2}{*}{ Vernagtbach } & cal. & 0.77 & 0.64 & 0.70 & 0.71 & 0.03 & 0.12 \\
\hline & val. & 0.87 & 0.75 & na & 0.83 & 0.03 & 0.14 \\
\hline \multirow[t]{2}{*}{ Obergurgl } & cal. & 0.84 & 0.80 & 0.89 & 0.89 & 0.04 & 0.04 \\
\hline & val. & 0.86 & 0.77 & 0.88 & 0.87 & 0.00 & 0.18 \\
\hline
\end{tabular}

gauges (Brunau, catchment outlet; Obergurgl and Vernagtbach, subcatchments without inflow) (Fig. 1). The calibration period was set from October 1993 to October 2000 and validation period from October 2000 to October 2008. A two years warming-up period was used to reach initial storage contents.

Locale climate scenarios and reanalysis data were generated for 19 precipitation stations and 10 temperature stations (Fig. 1) using the EDS method. The EDS method is an expanded regression approach including a side condition, which preserves the local variability (Bürger, 2002; Menzel and Bürger, 2002). For EDS one realisation of the ECHAM5 (GCM) A1B scenario run (IPCC, 2007) was used. Local scenarios were then available from October 2010 to October 2099 and reanalysis data were taken from October 1989 to October 2008. The generated data had a temporal resolution of one day, which defined the model time step.

\subsection{Model calibration and validation}

Values of 16 parameters were determined by calibration using Monte Carlo simulations. For each parameter lower and upper limits were received from HBV-D modeling experience and literature (Sælthun, 1996; Seibert, 1999). 2000 parameter sets were generated from a uniform distribution of given parameter ranges. The selection of the best parameter set was based on the goodness measure Nash-Sutcliffe Index (Nash and Sutcliffe, 1970), calculated with untransformed values (NSI_MEA) and log values (LNSI_MEA), and the relative volume error (VE_MEA). The goodness criteria were calculated on the base of daily observed and simulated discharge values.

\subsection{Model application with downscaled reanalysis data}

As an intermediate step between model calibration and model application with climate scenarios we applied the calibrated model with downscaled reanalysis data. This procedure was carried out in order to exclude that major model uncertainties were introduced by the differences in station availability between measured and downscaled data and the application of the downscaling method EDS. Therefore the resulting model performances using downscaled climate data (NSI_ANA, LNSI_ANA, VE_ANA) were compared with the corresponding goodness measures NSI_MEA, LNSI_MEA, VE_MEA. Additionally we calculated goodness criteria on the base of simulated discharge values using measured data input and simulated discharge values using reanalysis data for the entire catchment and entire simulation time.

\subsection{Model application with climate scenarios}

Future variations of water balance components (runoff, precipitation, evapotranspiration, glacier melt), temperature and fractional snow coverage were evaluated for the Ötztal using the calibrated model with constant glacier coverage from today and downscaled climate scenario data. Trends in annual terms were calculated using linear regression models. To evaluate trends in monthly values of areal runoff, precipitation, evapotranspiration and glacier melt areal mean monthly values from 2010 to 2055 were compared with areal mean monthly values from 2055 to 2099 . In order to assess the influence of the present state of glaciers on the hydrological regime of the Ötztaler Ache under consideration of future climate changes, runoff was additionally simulated assuming glaciers were completely melted, i.e. glacier coverage was set to $0 \%$. We compared the predictions of mean monthly runoff from October 2055 to October 2099 considering constant glacier coverage with predictions of mean monthly runoff assuming glaciers were completely melted.

\section{Results and discussion}

\subsection{Model calibration and validation}

Table 1 presents the goodness measures calculated with the best parameter set. NSI higher than 0.84, the world wide average NSI of temperature index models (Rango, 1992), were calculated for the entire catchment in the calibration period in $13 \%$ of all parameter sets. Thus, with only 2000 Monte Carlo simulations a satisfying parameter set was found. With the calibrated model comparable goodness measures were calculated for the validation period (Table 1). 
A)

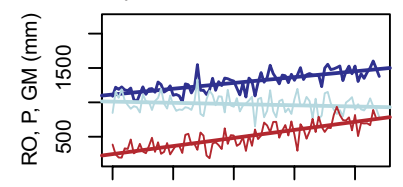

C)

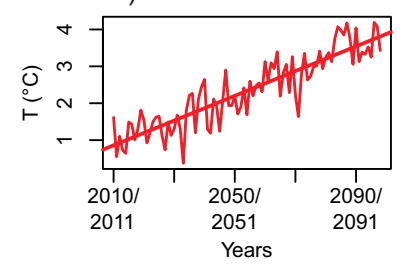

B)
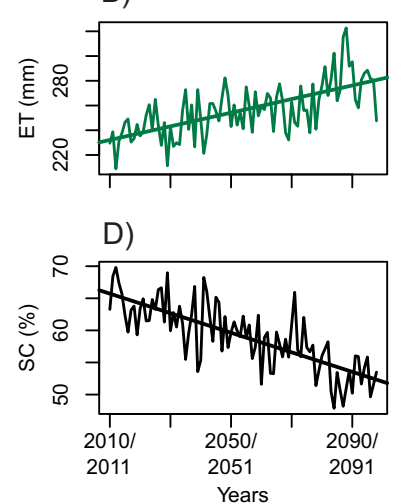

Fig. 2. Time series of annual areal terms of (A) runoff (RO, blue), precipitation ( $P$, lightblue) and glacier melt (GM, brown), (B) evapotranspiration (ET, green), $(\mathbf{C})$ temperature $(T$, red) and $(\mathbf{D})$ fractional snow coverage (SC, black) calculated using downscaled climate scenario data.

\subsection{Model application with downscaled reanalysis data}

The model performance of the calibrated model using reanalysis data was comparable to the calibrated model with the measured data (Table 1). Comparing the model outputs directly resulted into a NSI of 0.83 , LNSI of 0.95 and VE of 0.11 . This result indicates that the given differences in station availability or application of the downscaling method EDS might not introduce major uncertainties. However, comparing the model performances gave only an overall impression of the applicability of the model using different input data. As local differences between downscaled reanalysis data and observed data might be compensated in many different ways, this does not replace a detailed comparison between observed climate data and reanalysis data as carried out by Bürger (2002) or Menzel and Bürger (2002), for example. A decrease of model performance especially in the subcatchments might be caused by uncertainties of the EDS and reduced data availability.

\subsection{Model application with climate scenarios}

Figure 2 presents the time series of water balance components, temperature and fractional snow coverage for the current century. A positive trend was observed in runoff (increase of $422 \mathrm{~mm} / 100 \mathrm{a}$ ), glacier melt (increase of $587 \mathrm{~mm} / 100 \mathrm{a}$ ), evapotranspiration (increase of $55 \mathrm{~mm} / 100 \mathrm{a}$ ) and temperature (increase of $3.35^{\circ} \mathrm{C} / 100 \mathrm{a}$ ). A negative trend was observed in precipitation (decrease of $89 \mathrm{~mm} / 100 \mathrm{a}$ ) and fractional snow coverage (decrease of $15 \% / 100 \mathrm{a})$. Note that the high simulated values of runoff and glacier melt were resulting under the scenario of a constant glaciered area. Runoff increased particularly in summer and autumn, whereas precipitation decreased in summer and increased in winter (Fig. 3). An increase
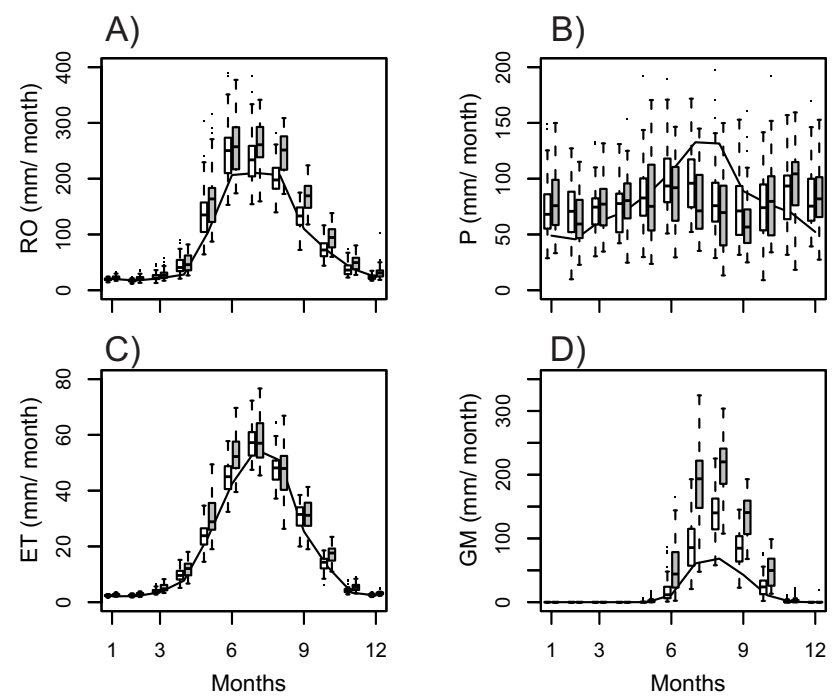

Fig. 3. Box plots of monthly areal values (A) of runoff (RO), (B) precipitation $(P),($ C) evapotranspiration $(E T)$ and $(D)$ glacier melt (GM). The boxes including values from 2010 to 2055 are plotted in white, boxes including values from 2055 to 2099 are in gray. As reference values median monthly simulated areal values from 1993-2008 are plotted with a black line.

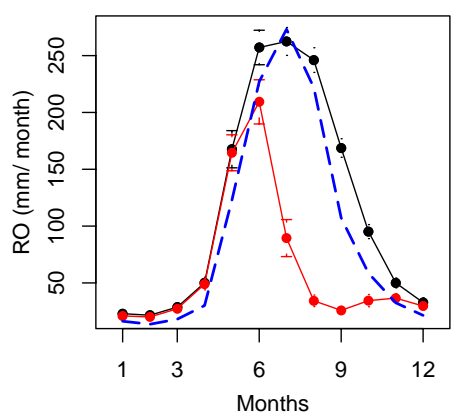

Fig. 4. Simulated mean monthly runoff (RO) at gauge Brunau with confidence interval bars using downscaled climate data from 2055 to 2099 with constant glacier coverage (black) and complete loss of glaciers (red). Measured mean monthly runoff from 1986 to 2008 is plotted in blue.

in evapotranspiration was observed from April to October (Fig. 3). As the applied model could not simulate a feedback between climate and vegetation, further changes in evapotranspiration, e.g. due to changes in vegetation composition, could be expected. Glacier melt doubled from June to October comparing monthly values from 2010 to 2055 with monthly values from 2055 to 2099 (Fig. 3). Intensification of the glacier melt in early summer indicated an earlier start of the glacier melt in future and a decrease in fractional snow coverage. After 2080 glacier melt started already in April. Temperature increased constantly throughout the year. While precipitation decreased and evapotranspiration increased in 
summer, the increase of runoff in summer and autumn was solely caused by the increase of glacier melt.

The model assumption of constant glacier coverage with contemporaneously intensification of glacier melt is unrealistic, but predetermined by the applied HBV-D model. In the context of climate change a retreat of glaciers is expected (e.g. Bogataj, 2007; European Environment Agency, 2009). Assuming a complete loss of glacier coverage, the simulation of runoff for the second half of the century showed an obvious decrease of runoff in summer and autumn (Fig. 4). Maximum loss of runoff by $86 \%$ was observed in August. Hagg and Braun (2005) modeled the reaction of runoff to climate change using two representive years for two highly glaciated subcatchments of the Ötztaler Ache catchment and also observed a decrease of summer runoff. The comparison of runoff simulations with two extreme assumptions of future glacier coverages presented in this study highlights the vulnerability of runoff of the Ötztaler Ache even though glaciers cover only $14 \%$ of the catchment. On the other hand, the study also shows clearly that reasonable prognosis for plausible runoff in the future in glaciered catchments like the Ötztal are impossible without considering glacier change! The land cover scenarios used in this study (stable glaciered area or complete loss of glaciered area) are a sort of extreme scenarios. Comparing the runoff predictions with today's runoff characteristics, an increase in winter and spring runoff was simulated (Fig. 4). This could be related to the increase of winter precipitation with higher percentage of rain instead of snow (Fig. 3) and the earlier start of snow and glacier melt. The trend towards reduced snow coverage could be explained by a temperature induced increase of elevation of snow line, which is also found by Bogataj (2007) and European Environment Agency (2009).

Finally one should consider that only one GCM output and only one possible climate scenario was used. Dobler and Stötter (2011), for example, pointed out that different realisations of climate scenarios could lead to significantly different results. Thus our results have to be regarded as one possible case study.

\section{Conclusions}

To simulate the response of the water balance to climate change in the Ötztaler Ache catchment the enhanced HBVD REG was successfully calibrated and validated with measured climate data. The application of the calibrated model with reanalysis data pointed out that plausible discharge data were simulated using local climate data downscaled by EDS. The investigations of model results using local climate scenarios showed an increase in mean areal temperature and a trend towards reduced precipitation. Average areal snow coverage decreased with time, whereas runoff in winter and spring increased towards the end of the current century. The information value of the model was limited by the use of constant glacier coverage. Implementing a dynamic glacier cover module in the HBV-D would improve the use of this model for climate change studies in areas influenced by glaciers significantly. The climate scenario, applied in this study, was only one possible future projection. Application of different climate change scenarios and different GCMs may assist to get a greater overview of possible future condition in the water balance in the Ötztal.

Acknowledgements. The authors like to gratefully acknowledge the following institutes for providing access to climate and geographical data: alps GmbH, Austria, TIWAG - Tiroler Wasserkraft AG, Austria, the Hydrographische Dienst Tirols, Austria, and the data portal "ehyd" from the BMLFUW - Bundesministerium für Land und Forstwirtschaft, Umwelt und Wasserwirtschaft, Austria. Furthermore we would like to thank PIK - Potsdam Institute For Climate Impact Research, Germany, providing the HBV-D and G. Bürger from the Pacific Climate Impacts Consortium, Canada, for the support in application of the downscaling method. The authors are also grateful for the access to the compute server of the University of Potsdam enabled the required extensive computations. Furthermore, the authors would like to thank two anonymous reviewers for the constructive and encouraging comments and suggestions.

Edited by: K. Schneider and S. Achleitner

Reviewed by: two anonymous referees

\section{References}

Bergström, S.: The HBV model, Chap. 13, 443-476, Water Resources Publications Littleton, Colorado, USA, 1995.

BMLFUW: Hydrologischer Atlas Österreichs, 2007.

Bogataj, L.: How will the Alps Respond to Climate Change?, Alpine space - man \& environment, 3, 43-51, 2007.

Bürger, G.: Selected precipitation scenarios across Europe, J. Hydrol., 262, 99-110, 2002.

Dobler, C. and Stötter, J.: Assessing the Impacts of Climate Change on Flood Frequency in an Alpine Watershed., in: Managing Alpine Future II, International Conference 2011, Innsbruck, 2011.

European Environment Agency: EEA SIGNALS 2009, Key environmental issues facing europe, 2009.

Gómez, J., Etchevers, J., Monterroso, A., Gay, C., Campo, J., and Martínez, M.: Spatial estimation of mean temperature and precipitation in areas of scarce meteorological information, Atmósfera, 21, 35-56, 2008.

Hagg, W. and Braun, L.: The Influence of Glacier Retreat on Water Yield from High Mountain Areas: Comparison of Alps and Central Asia, Climate and hydrology in mountain areas, p. 263, 2005.

Hydrographischer Dienst in Österreich: Hydrographisches Jahrbuch von Österreich, Tech. rep., Bundesministerium für Land- und Forstwirtschaft, Umwelt und Wasserwirtschaft Abteilung VII/3 - Wasserhaushalt, 2009.

IPCC: The Physical Science Basis. Contribution of Working Group I to the Fourth Assessment Report of the Intergovernmental Panel 
on Climate Change, Cambridge University Press, Cambridge, United Kingdom and New York, NY, USA, 996 pp., 2007.

Krysanova, V., Bronstert, A., and Müller-Wohlfeil, D.: Modelling river discharge for large drainage basins: from lumped to distributed approach, Hydrolog. Sci. J., 44, 313-331, 1999.

Marquinez, J., Lastra, J., and Garcia, P.: Estimation models for precipitation in mountainous regions: the use of GIS and multivariate analysis, J. Hydrol., 270, 1-11, 2003.

Menzel, L. and Bürger, G.: Climate change scenarios and runoff response in the Mulde catchment (Southern Elbe, Germany), J. Hydrol., 267, 53-64, 2002.

Nash, J. and Sutcliffe, J.: River flow forecasting through conceptual models part I - A discussion of principles, J. Hydrol., 10, 282290, 1970.

Psenner, R. and Lackner, R.: Die Alpen im Jahr 2020, Innsbruck University Press, 2006.

Rango, A.: Worldwide testing of the snowmelt runoff model with applications for predicting the effects of climate change, Nord. Hydrol., 23, 155-172, 1992.

Röthlisberger, H. and Lang, H.: Glacial hydrology, in: Glaciofluvial sediment transfer, edited by: Gurnell, A. and Clark, M., 207-284, John Wiley \& Sons, 1987.
Sælthun, N.: The Nordic HBV model, Norwegian Water Resources and Energy Administration Publication, 7, 1-26, 1996.

Schaefli, B., Hingray, B., Niggli, M., and Musy, A.: A conceptual glacio-hydrological model for high mountainous catchments, Hydrol. Earth Syst. Sci., 9, 95-109, doi:10.5194/hess-9-95-2005, 2005.

Seibert, J.: Regionalisation of parameters for a conceptual rainfallrunoff model, Agr. Forest Meteorol., 98, 279-293, 1999.

Tecklenburg, C.: Modellierung des Wasserhaushaltes des Ötztals (Tirol) unter Berücksichtigung von Klimaänderungen, Master's thesis, University of Potsdam, 2011.

Tecklenburg, C., Kormann, C., Francke, T., and Bronstert, A.: On the importance of high-altitude climate stations and climate data interpolation in conceptual hydrological modeling in high mountain areas, Hydrol. Res., under review, 2012.

Veit, H.: Die Alpen: Geoökologie und Landschaftsentwicklung, Vol. 2327, UTB/Ulmer, 2002.

Wilby, R. and Wigley, T.: Downscaling general circulation model output: a review of methods and limitations, Prog. Phys. Geog., 21, 530-548, 1997. 